Supporting Information

\title{
Development of a Scalable Synthesis of trans-4- Fluorocyclohexylamine via Directed Hydrogenation
}

\author{
Joyce C. Leung, ${ }^{*}+$ Thach T. Nguyen ${ }^{\dagger}$ Mariusz Krawiec,,${ }^{\ddagger}$ Donghong A. Gao $\neq$ and \\ Jonathan T. Reeves ${ }^{\dagger}$
}

Chemical Development ${ }^{\dagger}$ and Material and Analytical Sciences, ${ }^{\ddagger}$ Boehringer Ingelheim Pharmaceuticals, Inc., 900 Ridgebury Road, Ridgefield, Connecticut 06877-0378, USA 
${ }^{1} \mathrm{H}$ NMR-21

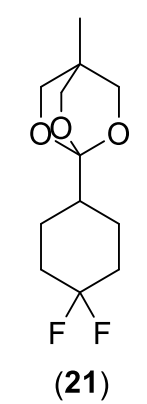

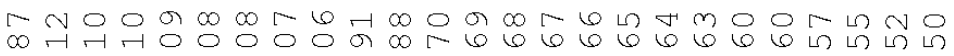

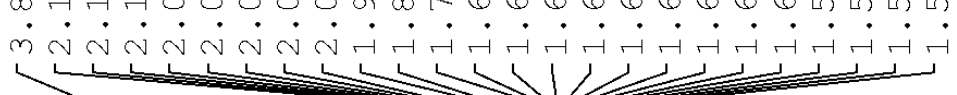

(21)
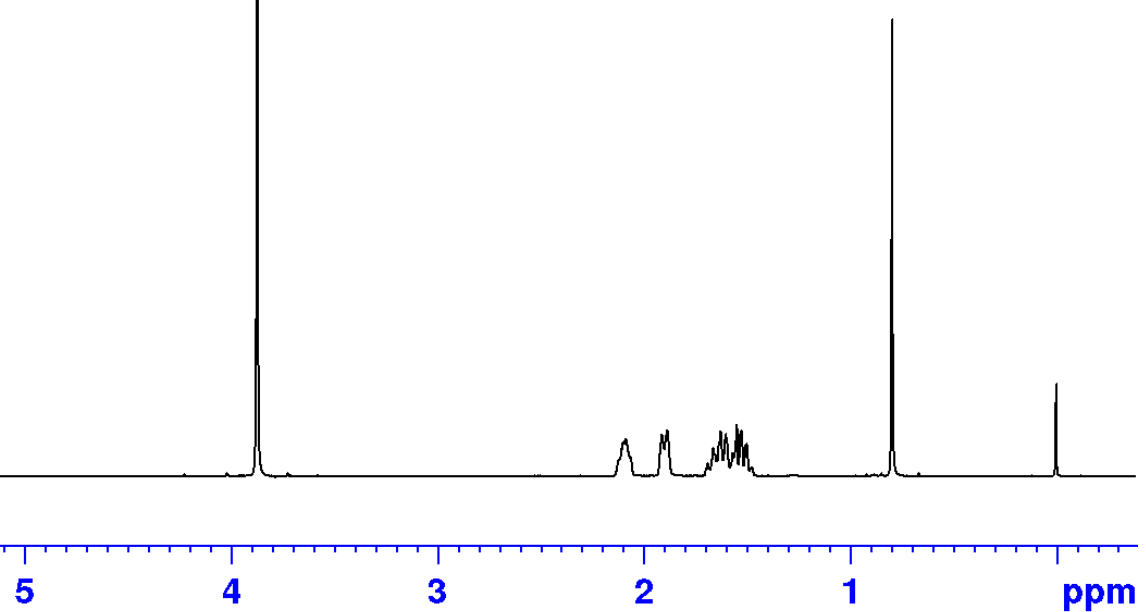
$\left|\begin{array}{l}4 \\ 0 \\ 0 \\ 0\end{array}\right|$

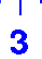

2

1

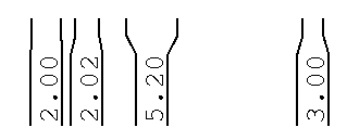

ppm 
${ }^{13} \mathrm{C}$ NMR-21
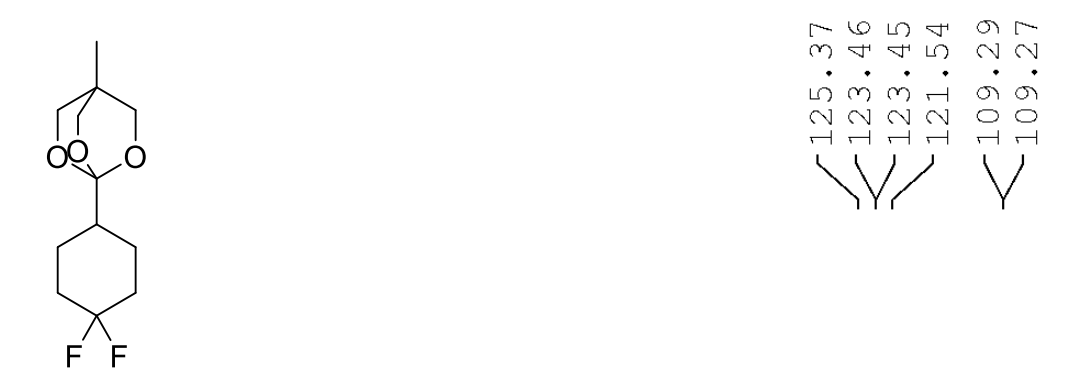

a
$\stackrel{N}{N}$

の $\infty \infty 6 \infty \infty 6 \infty 6$

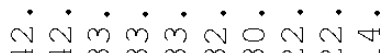

WI

(21)

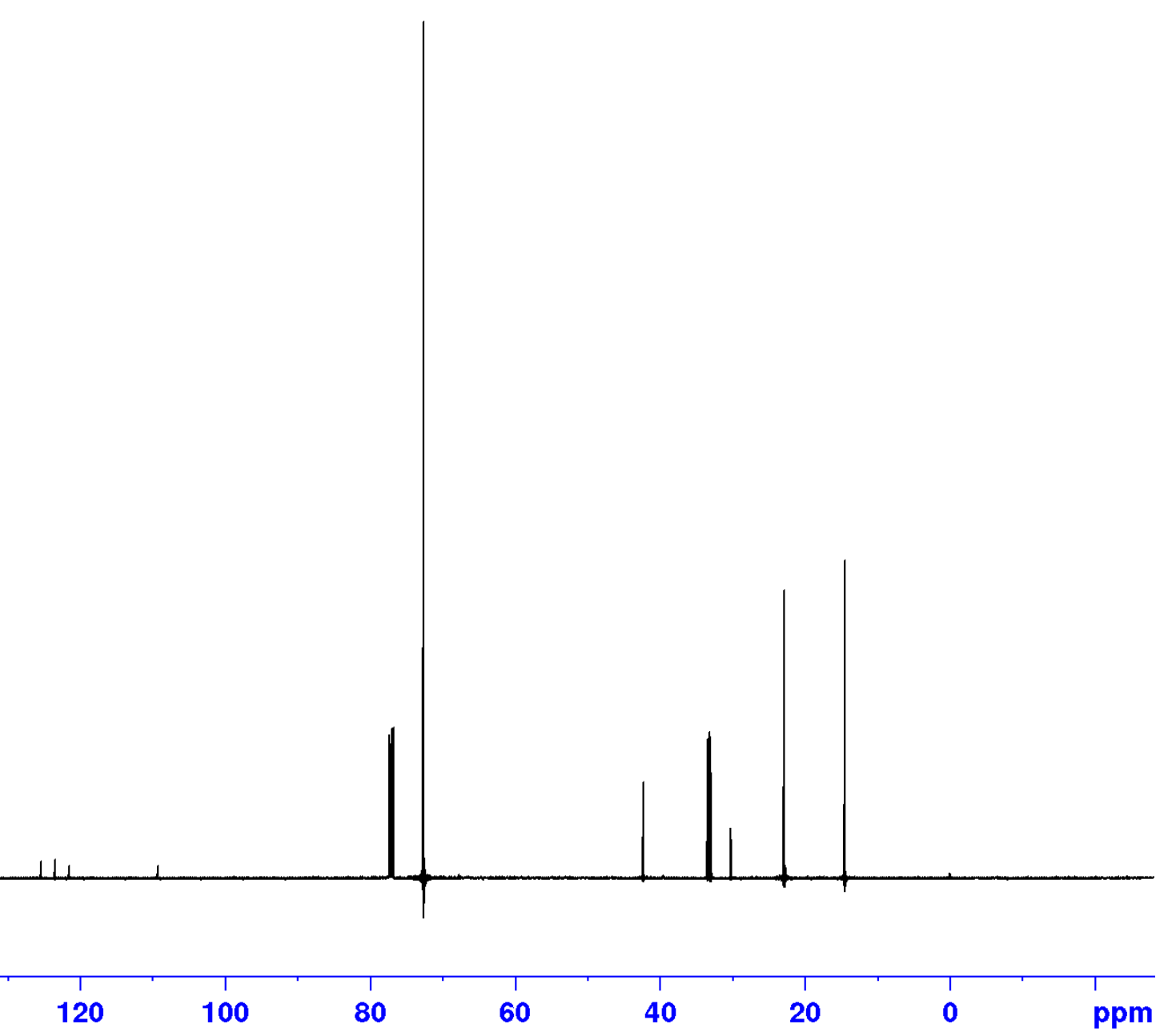




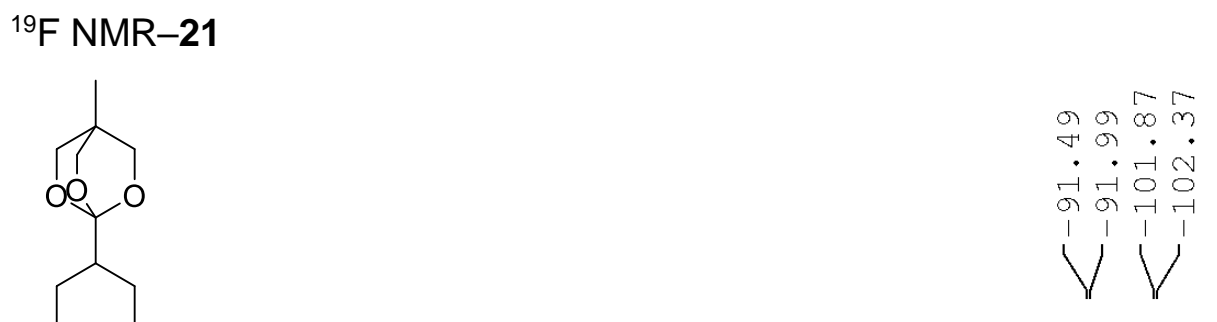

(21)

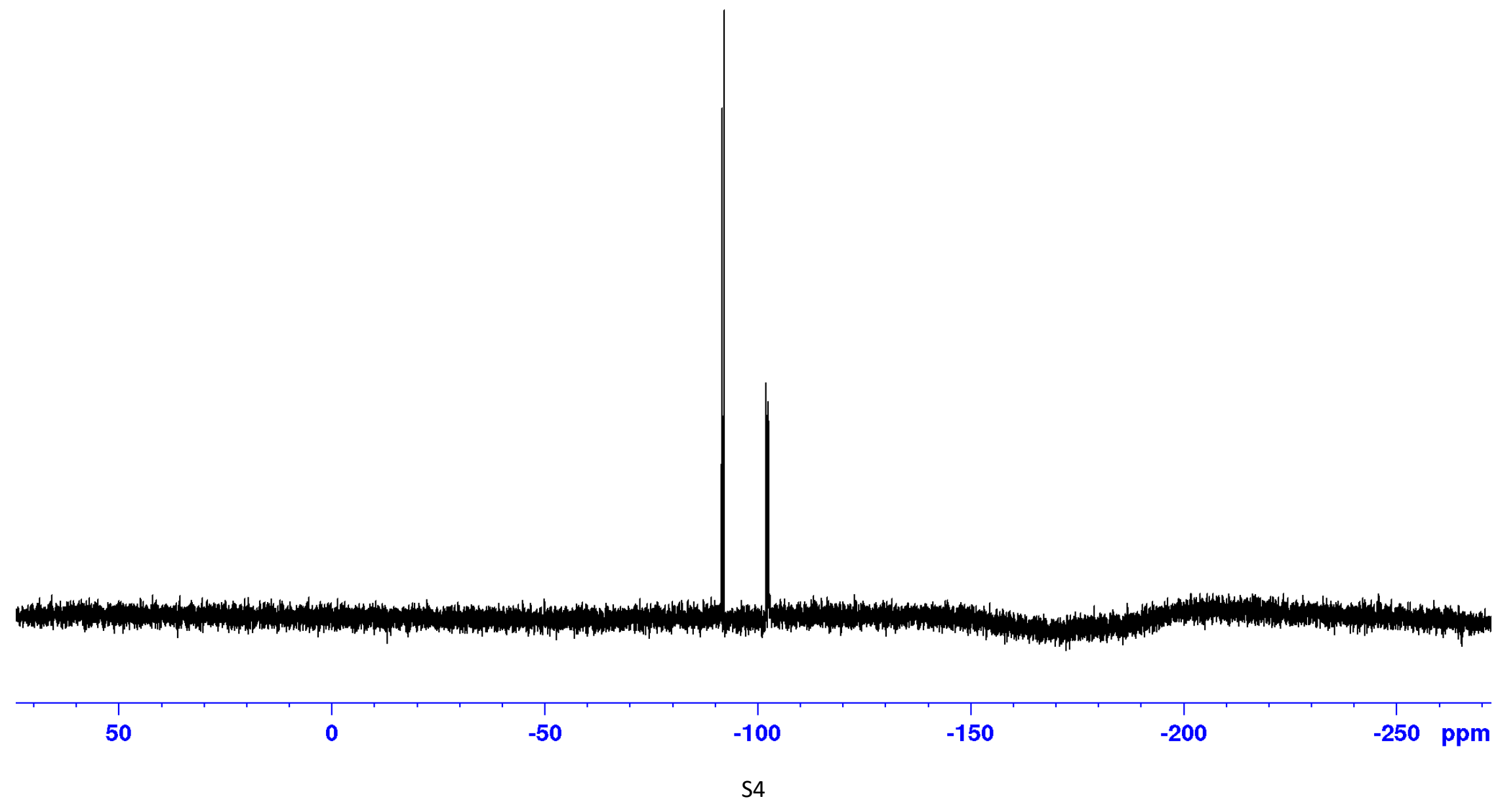


${ }^{1}$ H NMR-22

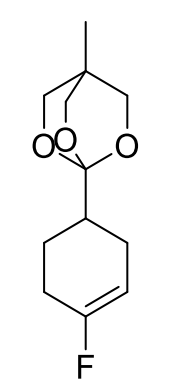

en ن

(22)

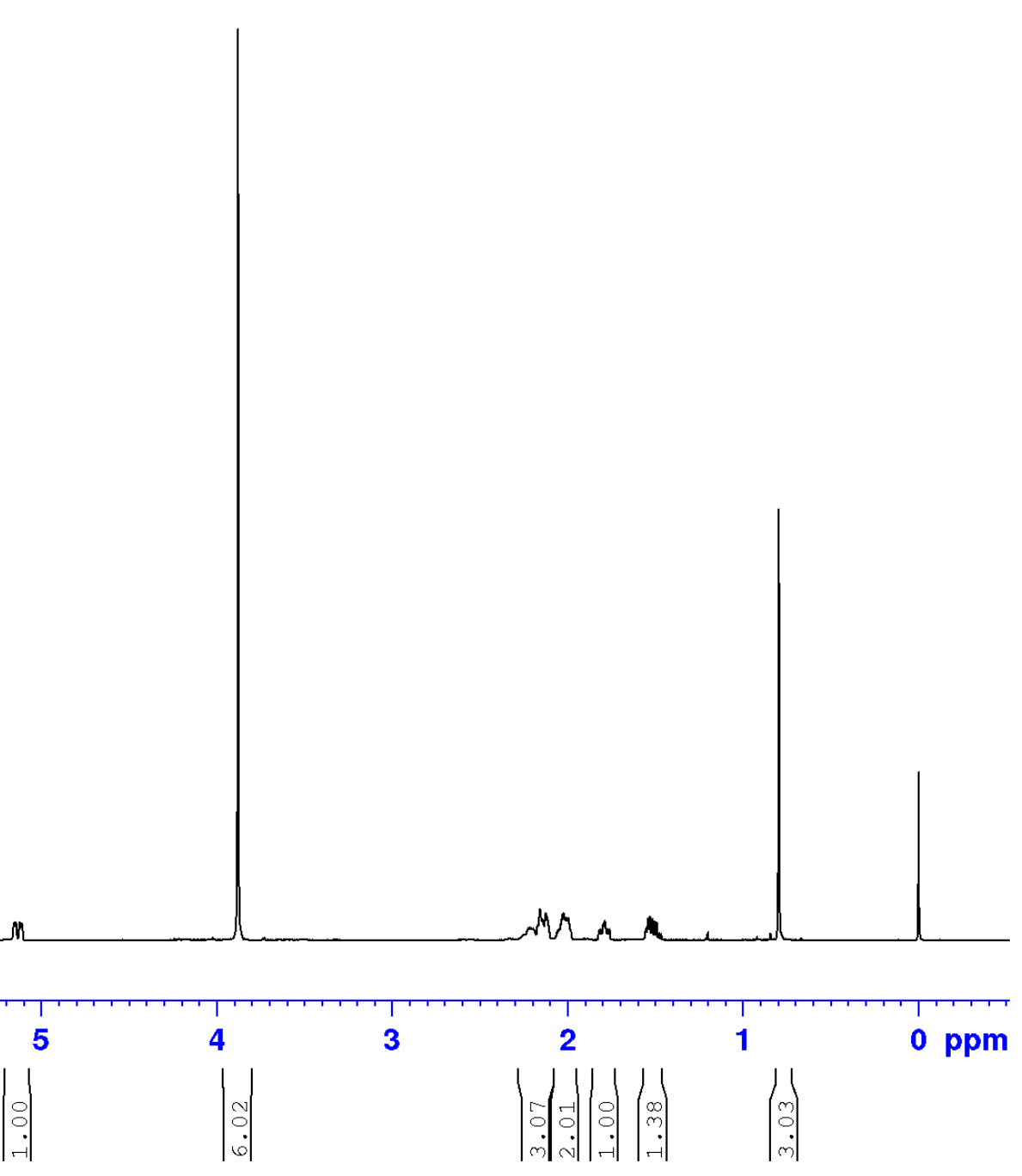


${ }^{13} \mathrm{C}$ NMR-22
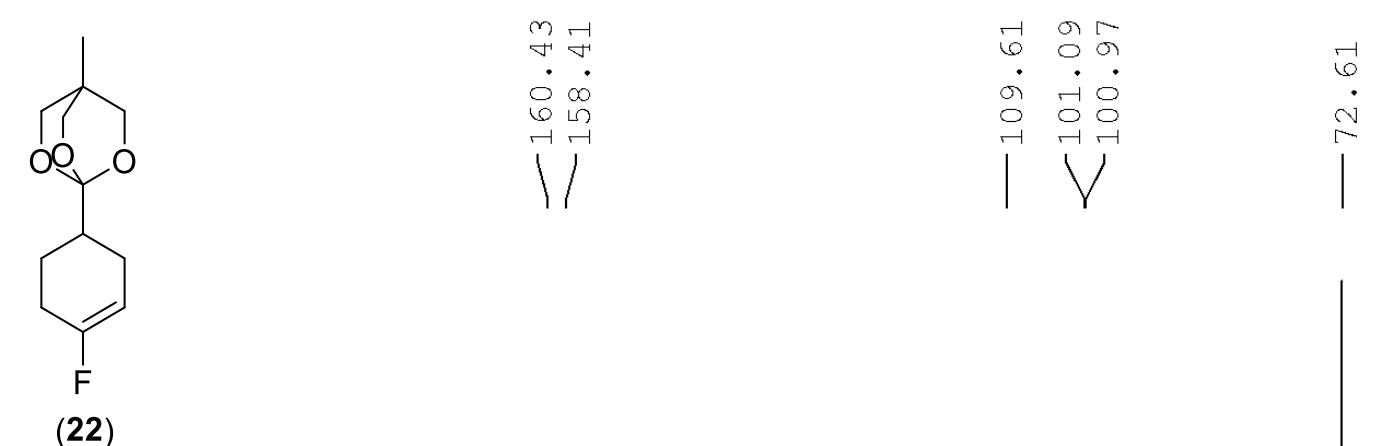

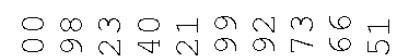

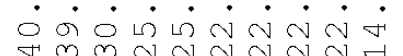

13

(22)

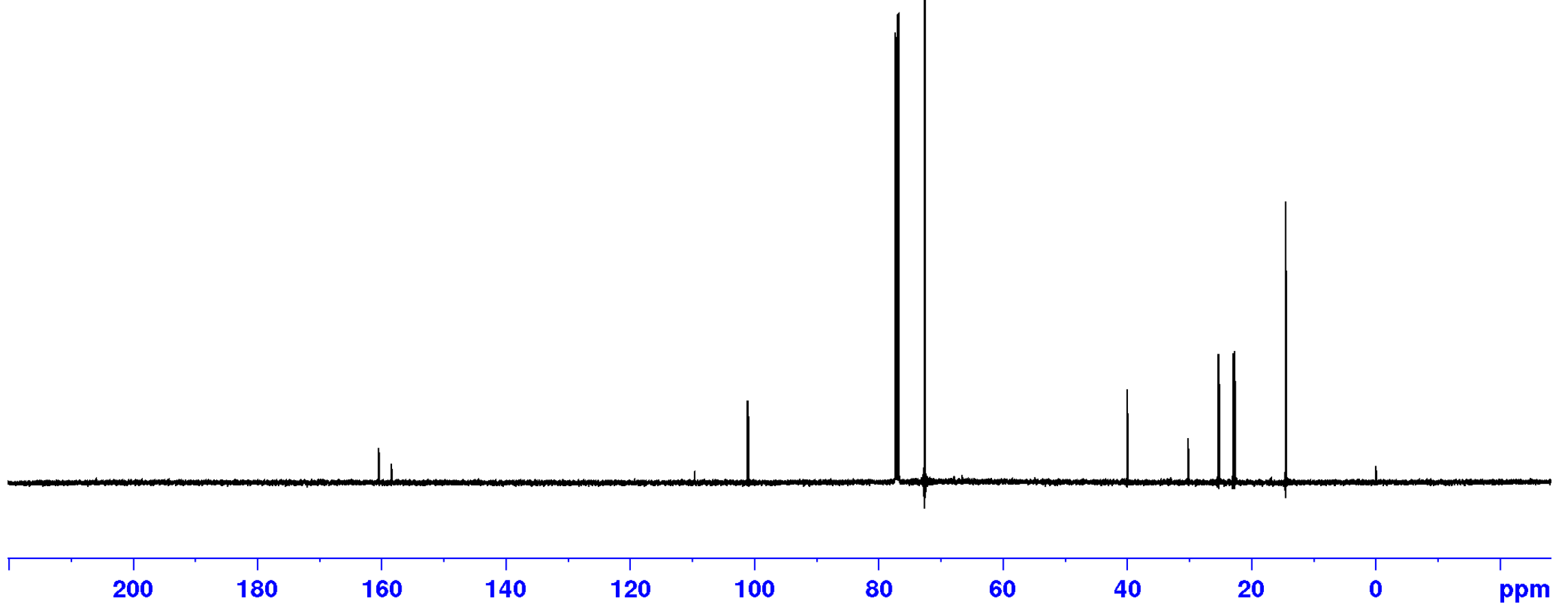


${ }^{19} \mathrm{~F}$ NMR-22

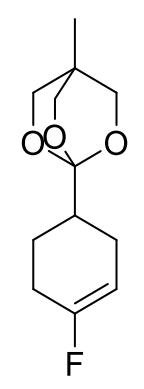

(22)

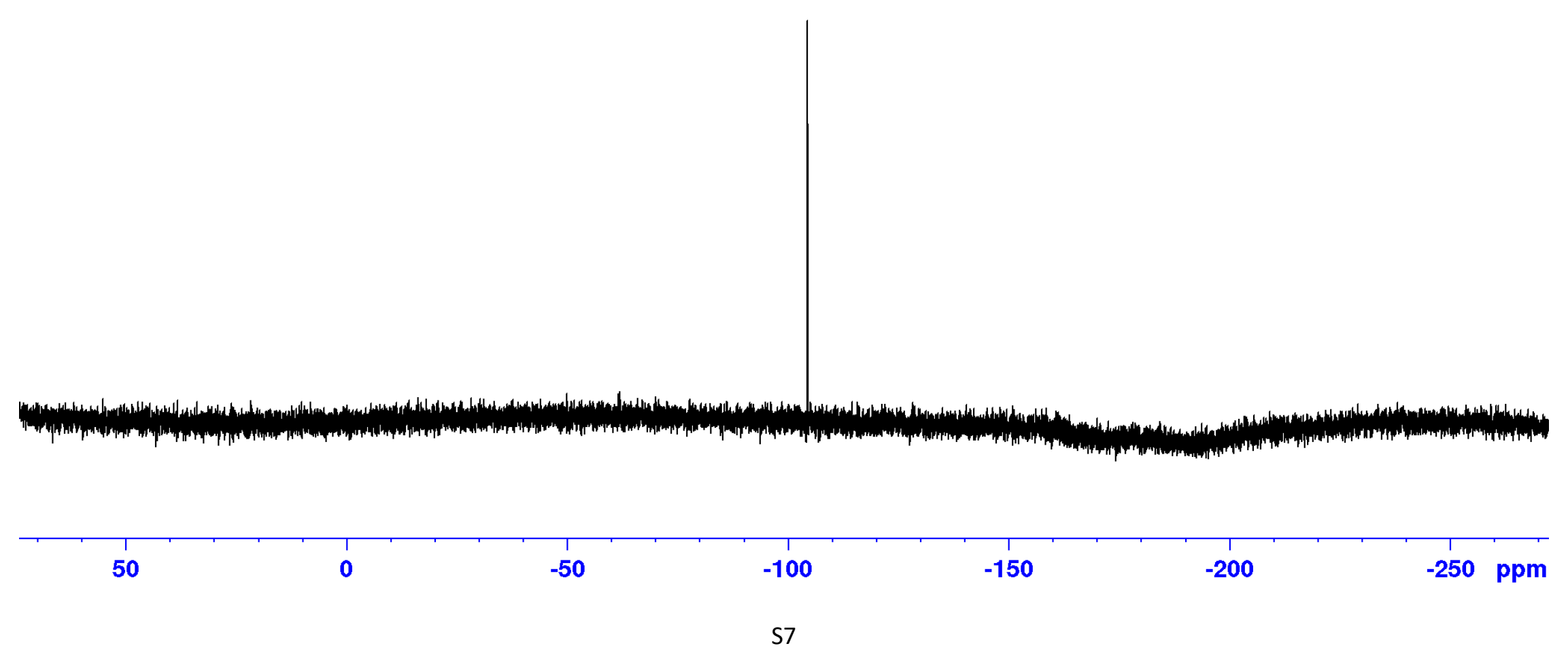


${ }^{1} \mathrm{H}$ NMR-15

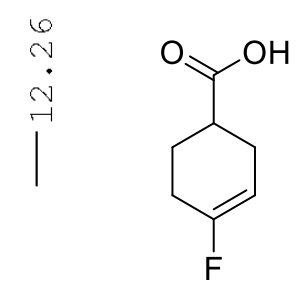

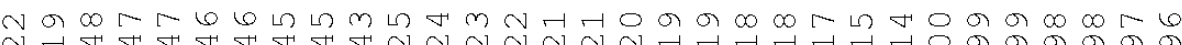

$\dot{\sim} \dot{\sim} \dot{\sim} \dot{\sim} \dot{\sim} \dot{\sim} \dot{\sim} \dot{\sim} \dot{\sim} \dot{\sim} \dot{\sim} \dot{\sim} \dot{\sim} \dot{\sim} \dot{\sim} \dot{\sim} \dot{\sim} \dot{\sim} \dot{\sim} \dot{\sim} \dot{\sim} \dot{\sim} \dot{H} \dot{H} \dot{H} \dot{H} \dot{H}$ $\rightarrow$

(15)

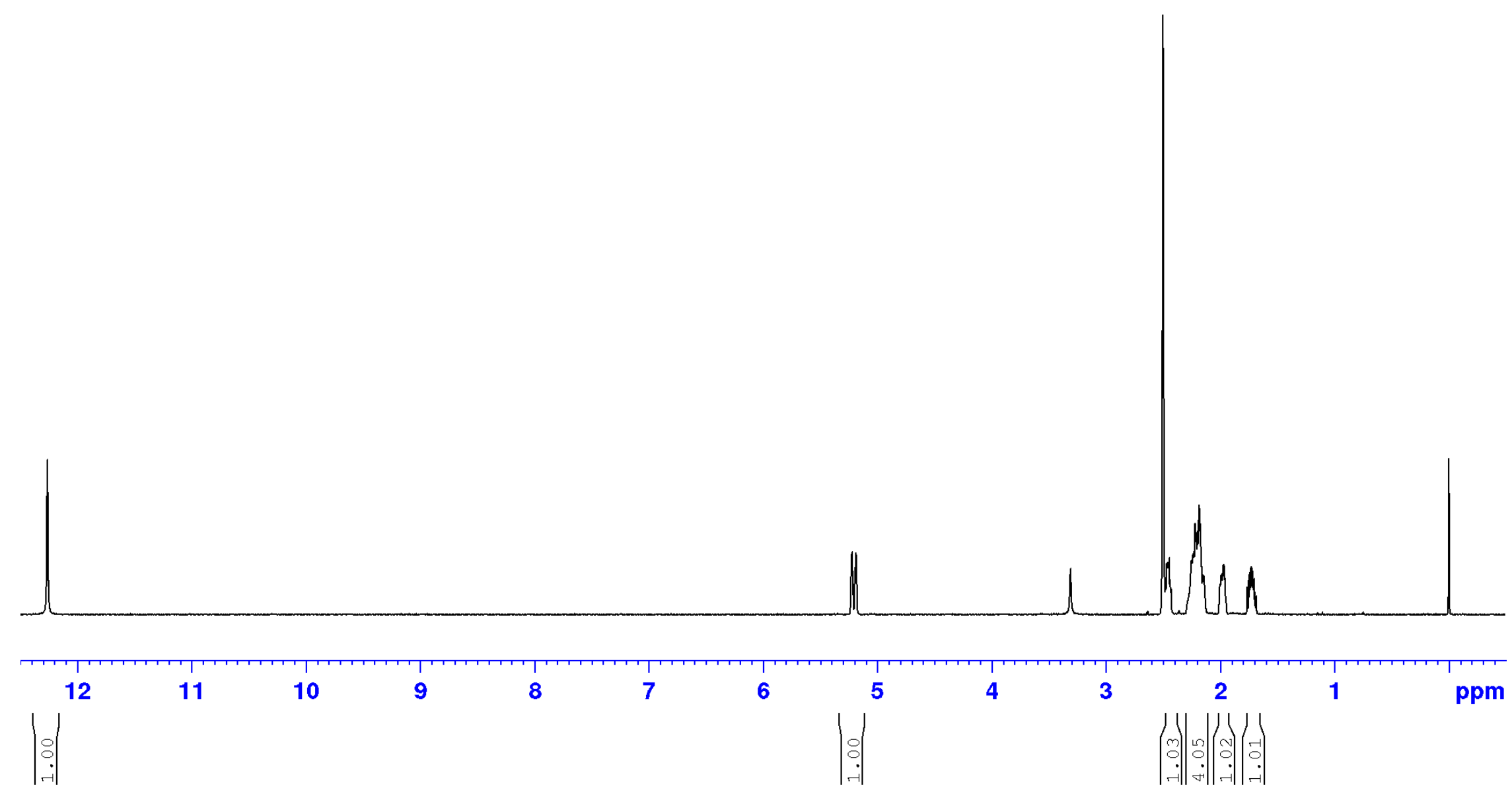


${ }^{13} \mathrm{C}$ NMR-15

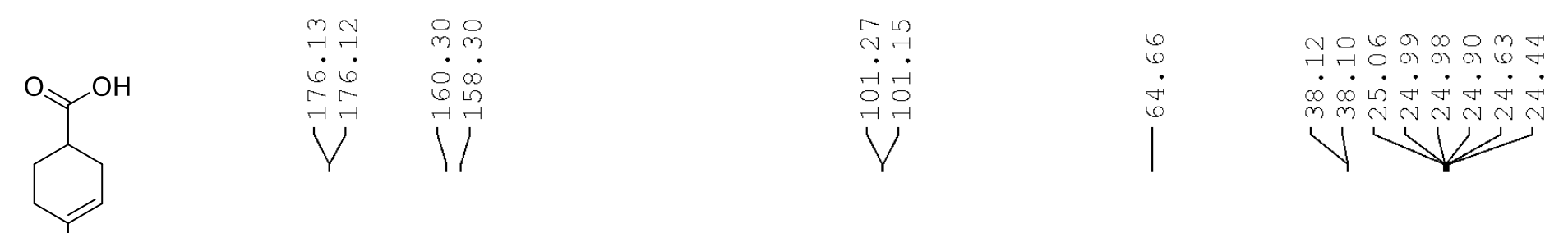

(15)

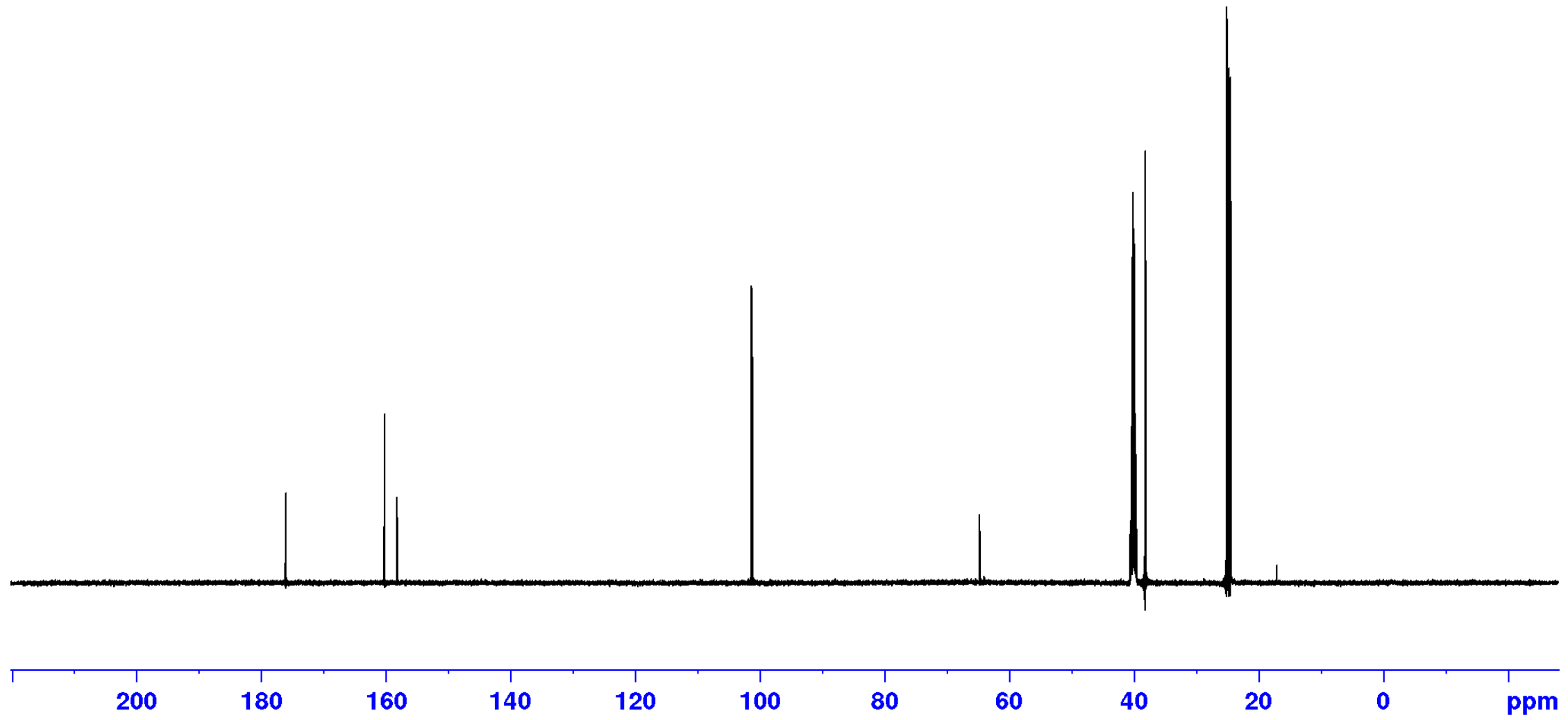


${ }^{19} \mathrm{~F}$ NMR-15

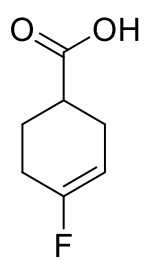

(15)

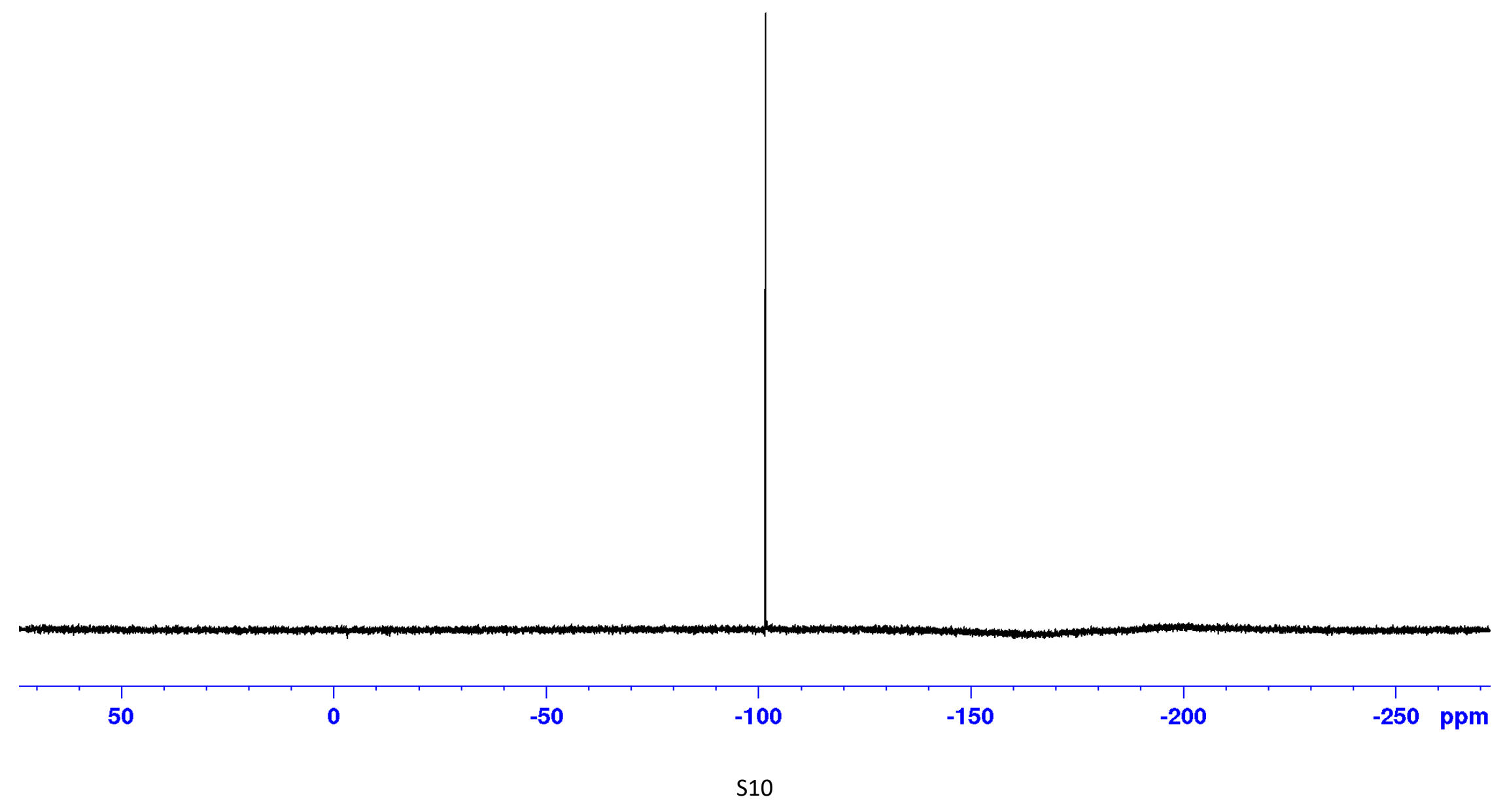


${ }^{1} \mathrm{H}$ NMR-16

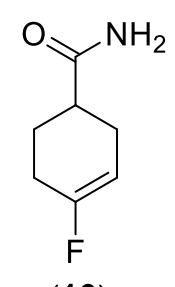

(16)

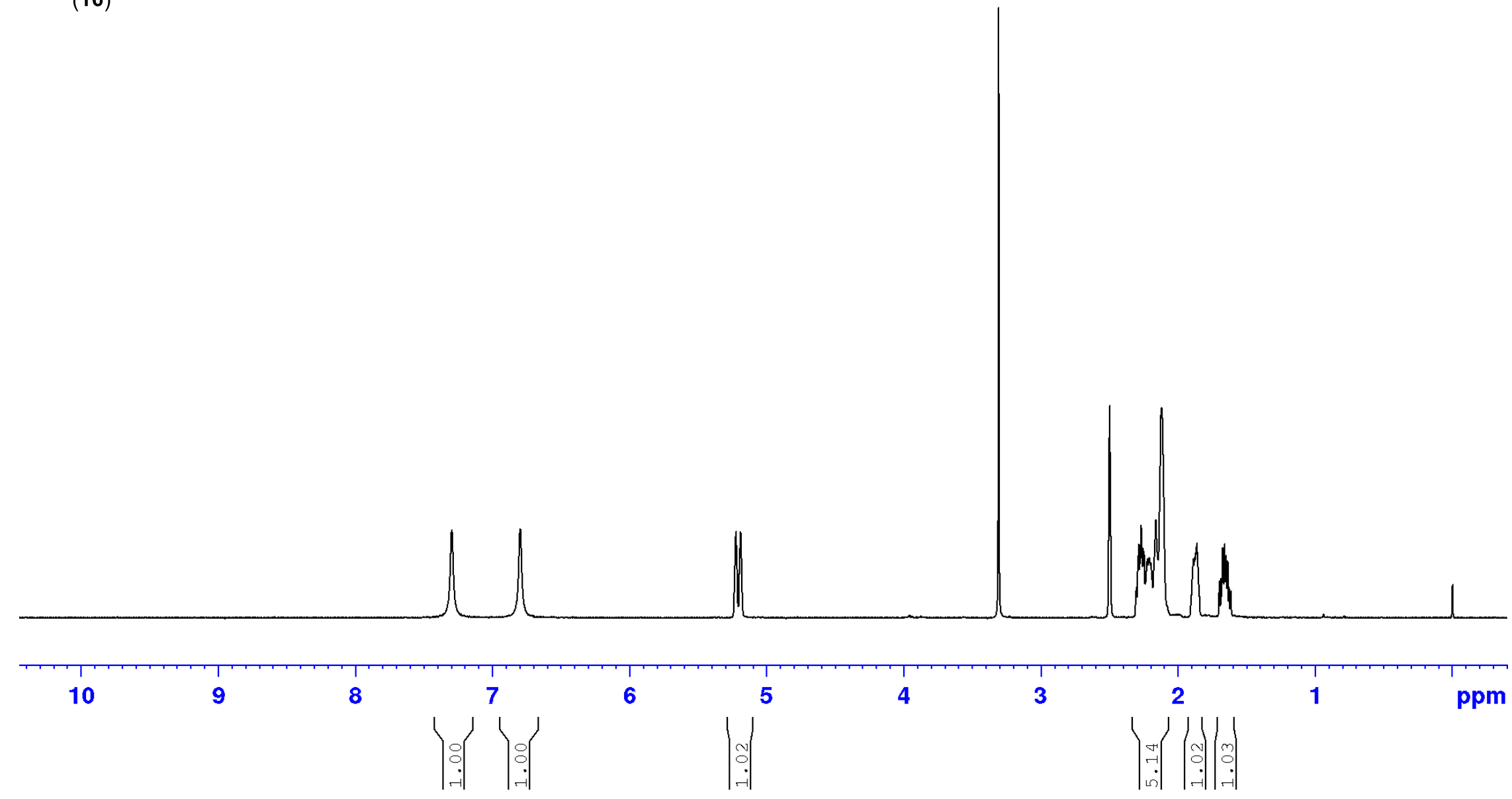


${ }^{13} \mathrm{C}$ NMR-16

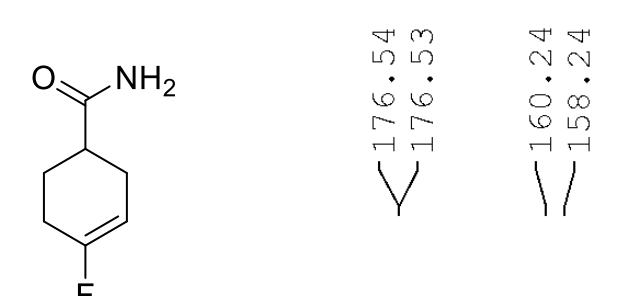

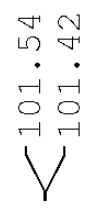

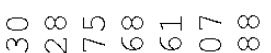

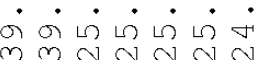

V vif

(16)

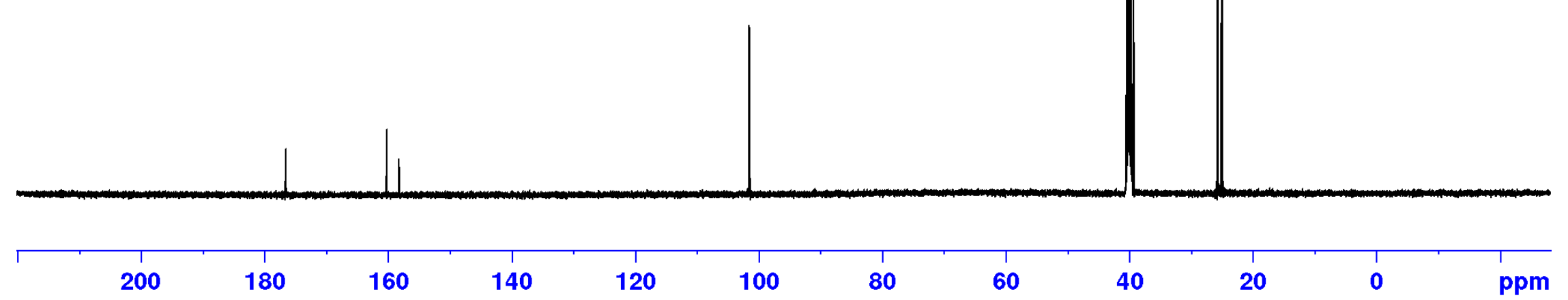


${ }^{19} \mathrm{~F}$ NMR-16

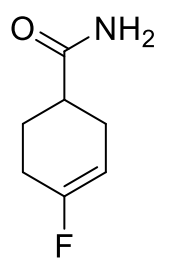

검
검

(16)

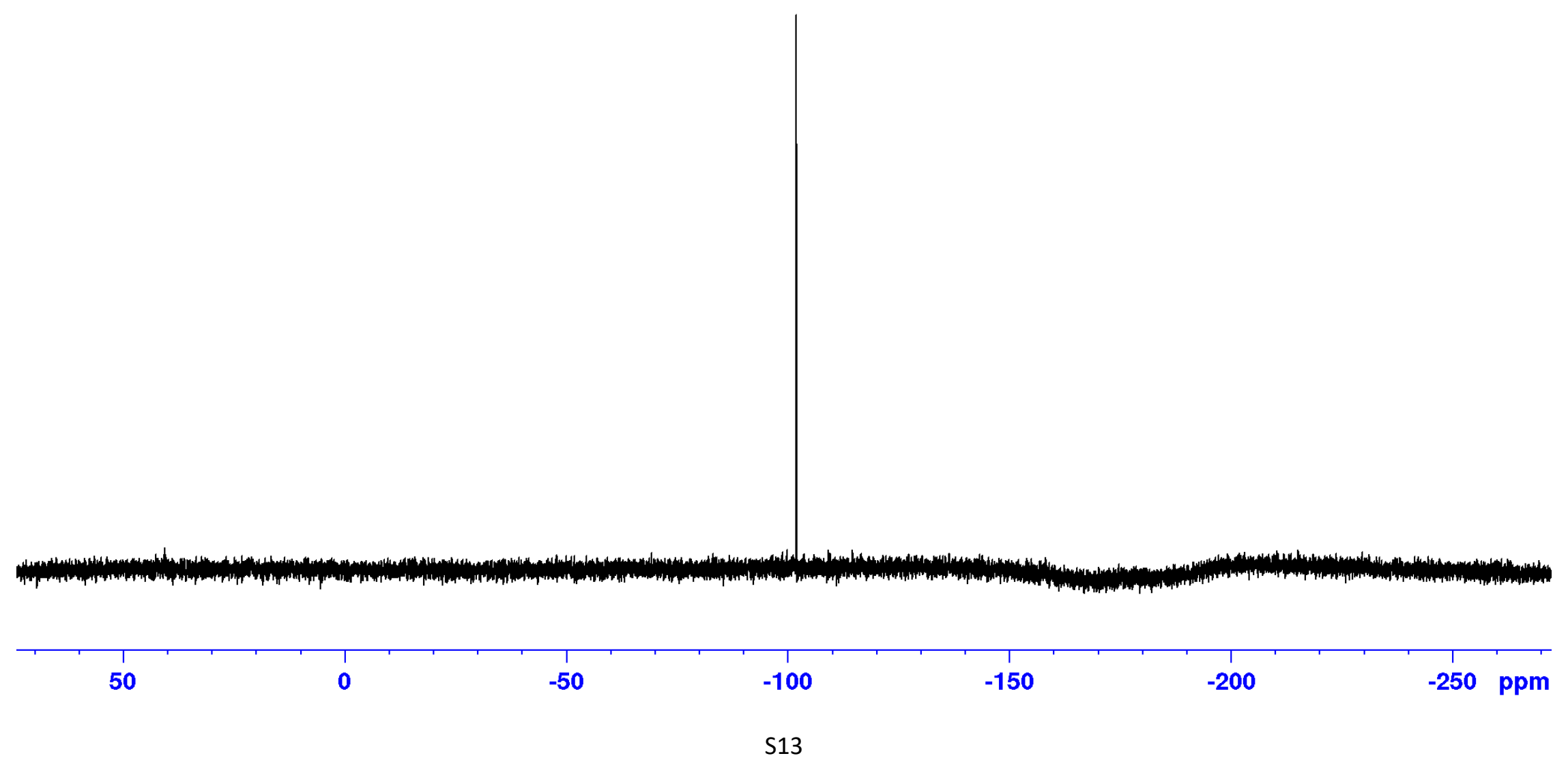


${ }^{1} \mathrm{H}$ NMR-17c

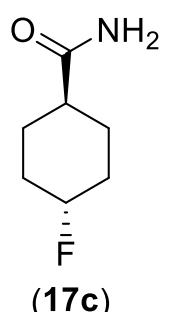

$\stackrel{v}{i}$

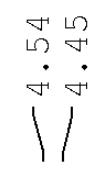

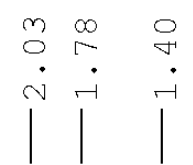

(17c)

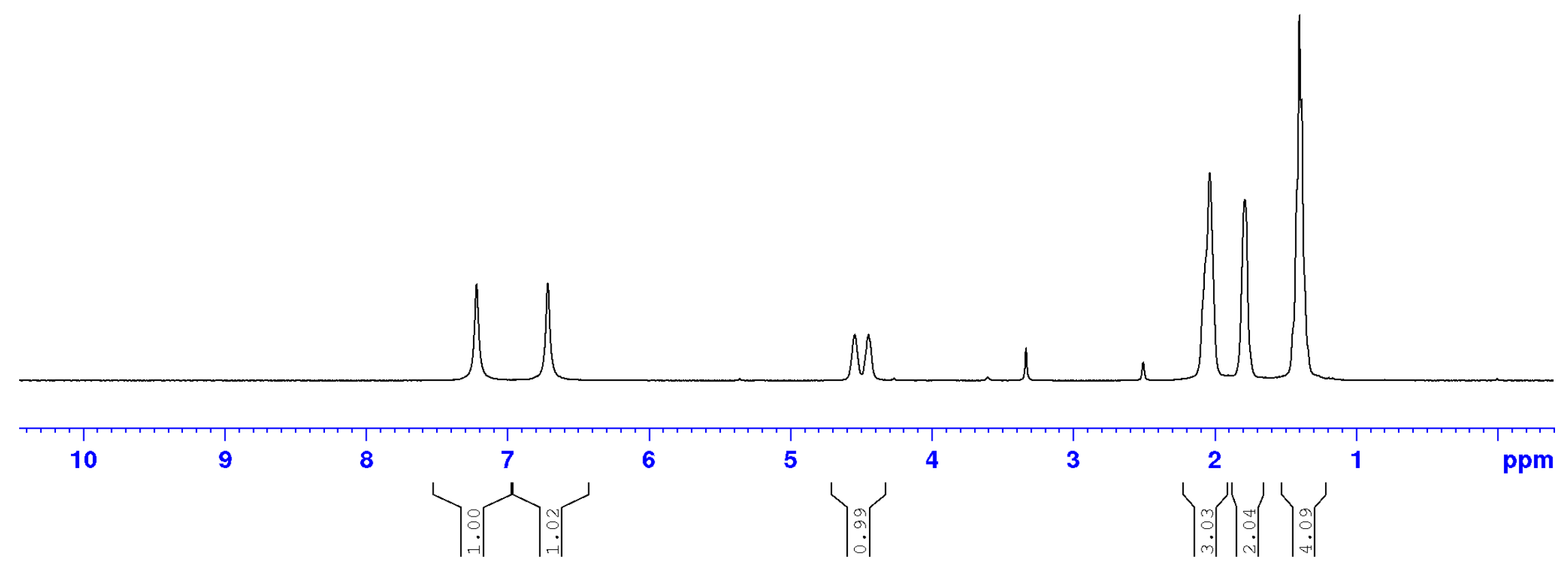


${ }^{13} \mathrm{C}$ NMR-17c
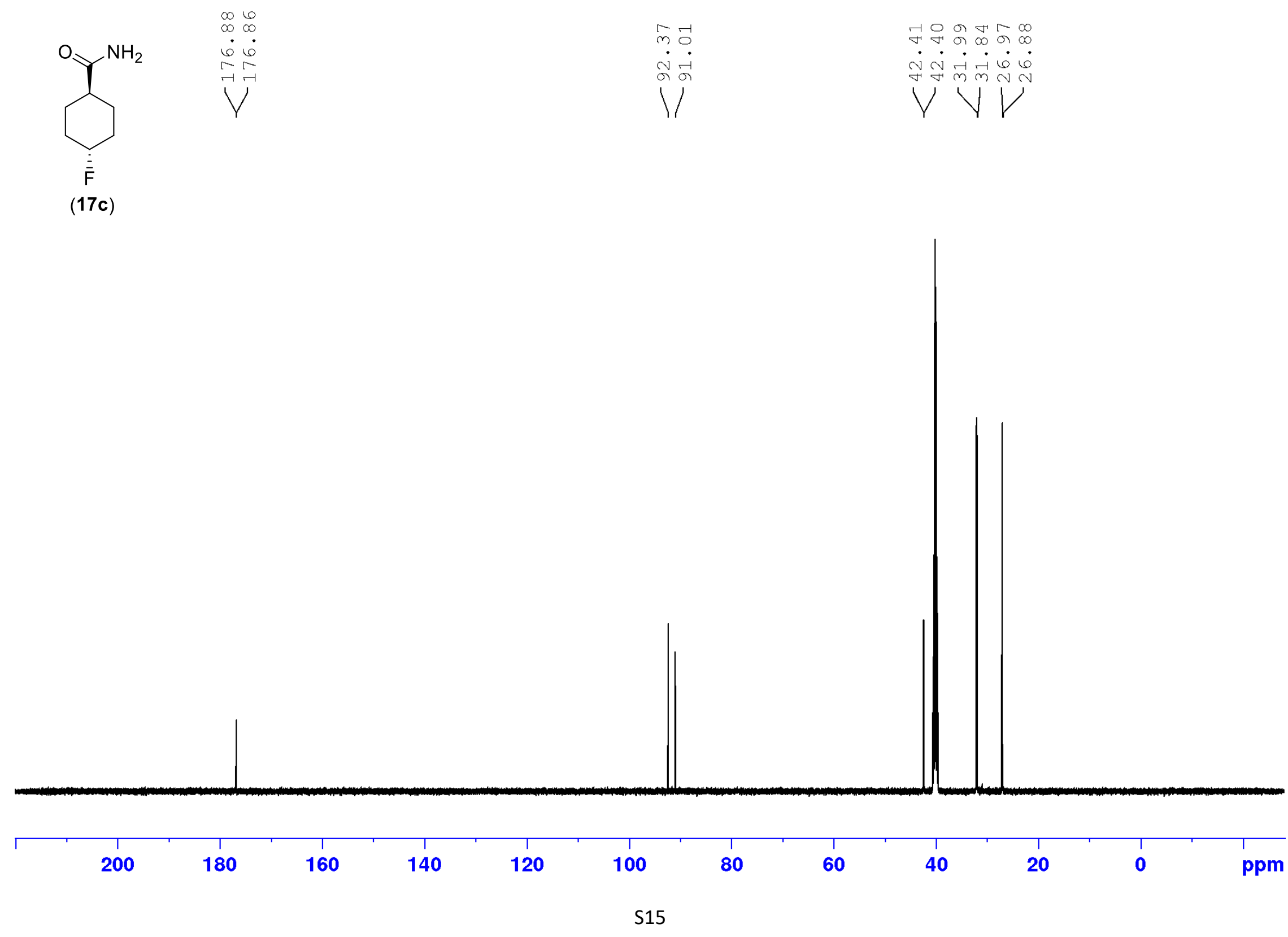
${ }^{19} \mathrm{~F}$ NMR-17c
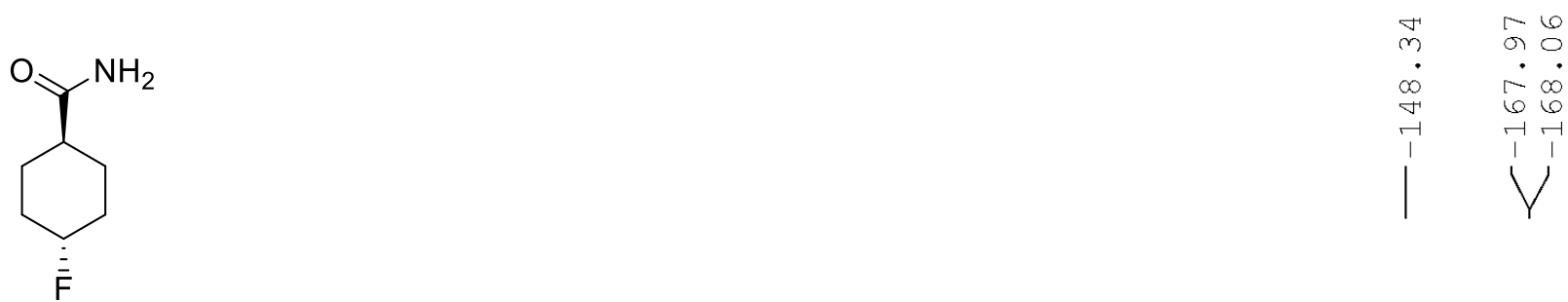

(17c)

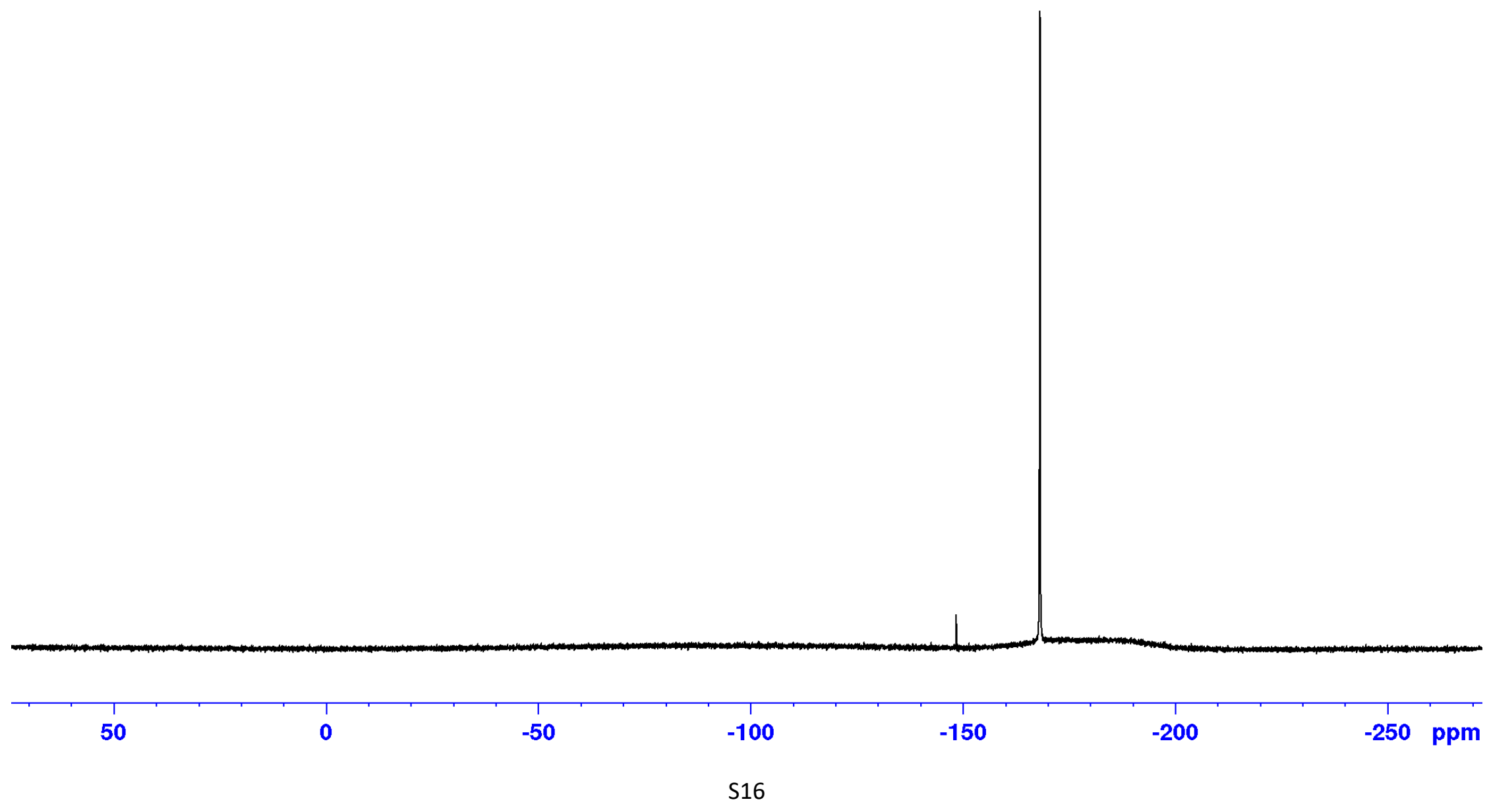


${ }^{1} \mathrm{H}$ NMR-1a

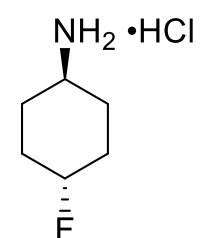

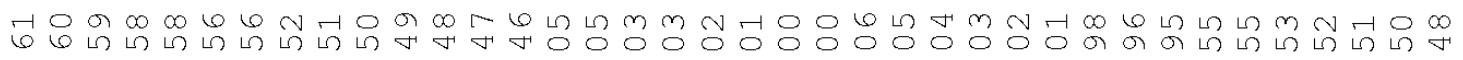

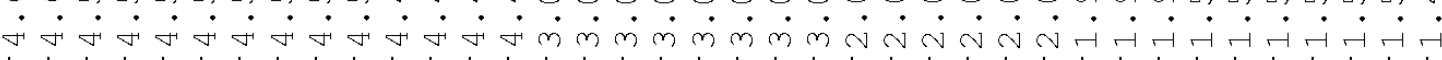

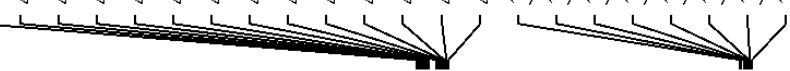

(1a)

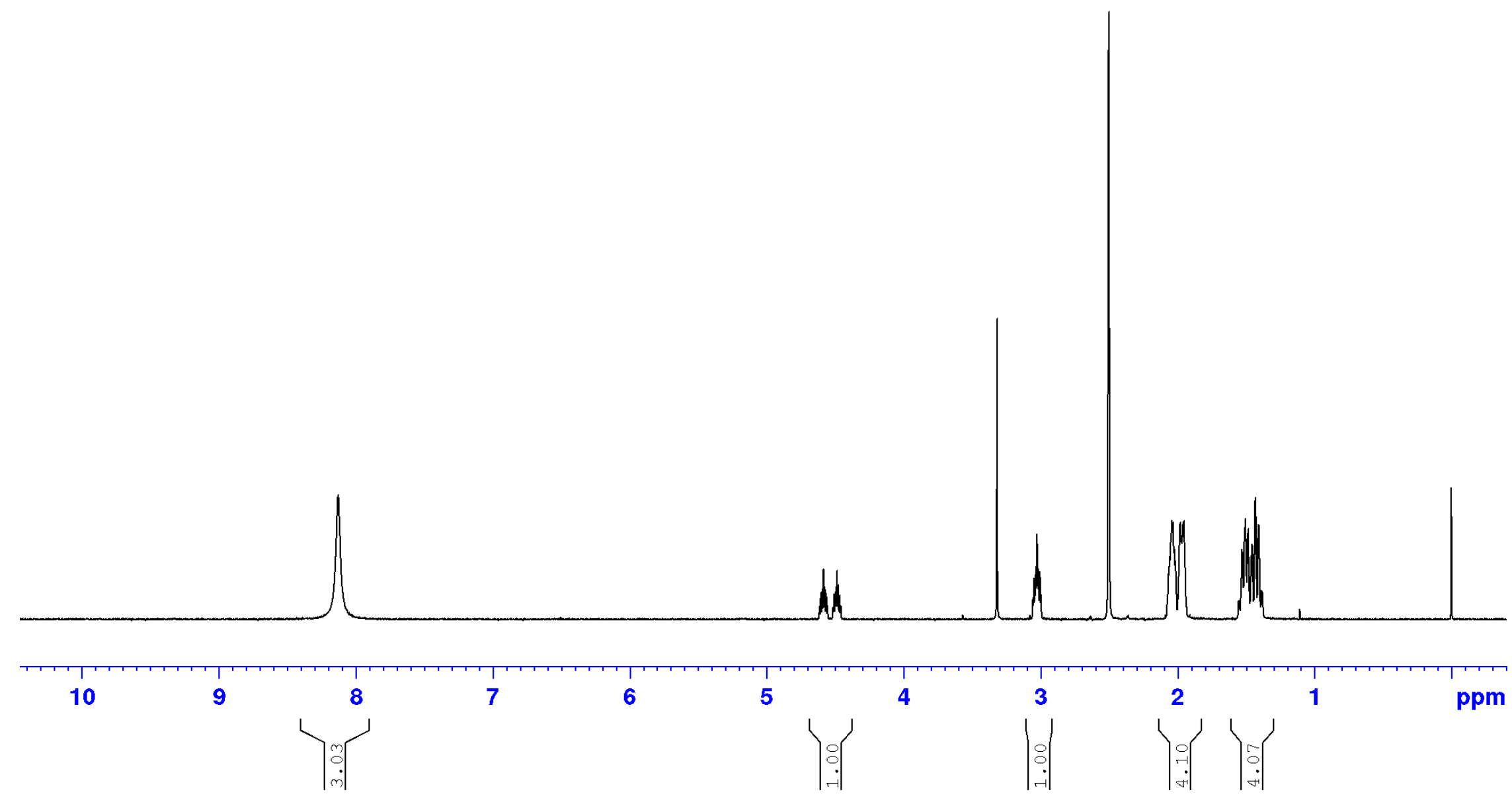


${ }^{13} \mathrm{C}$ NMR-1a
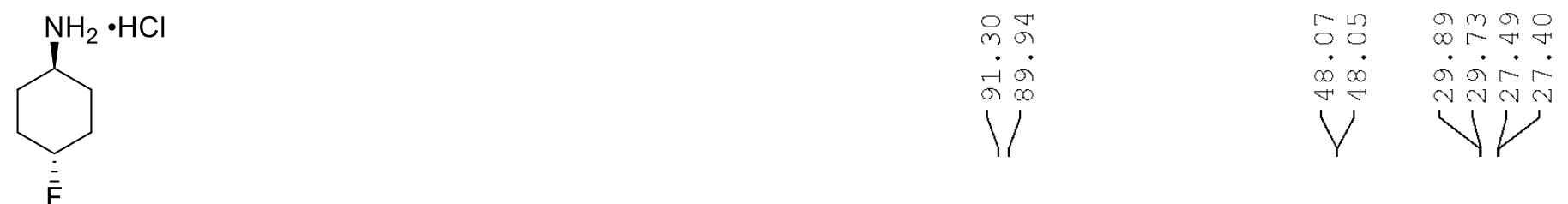

(1a)

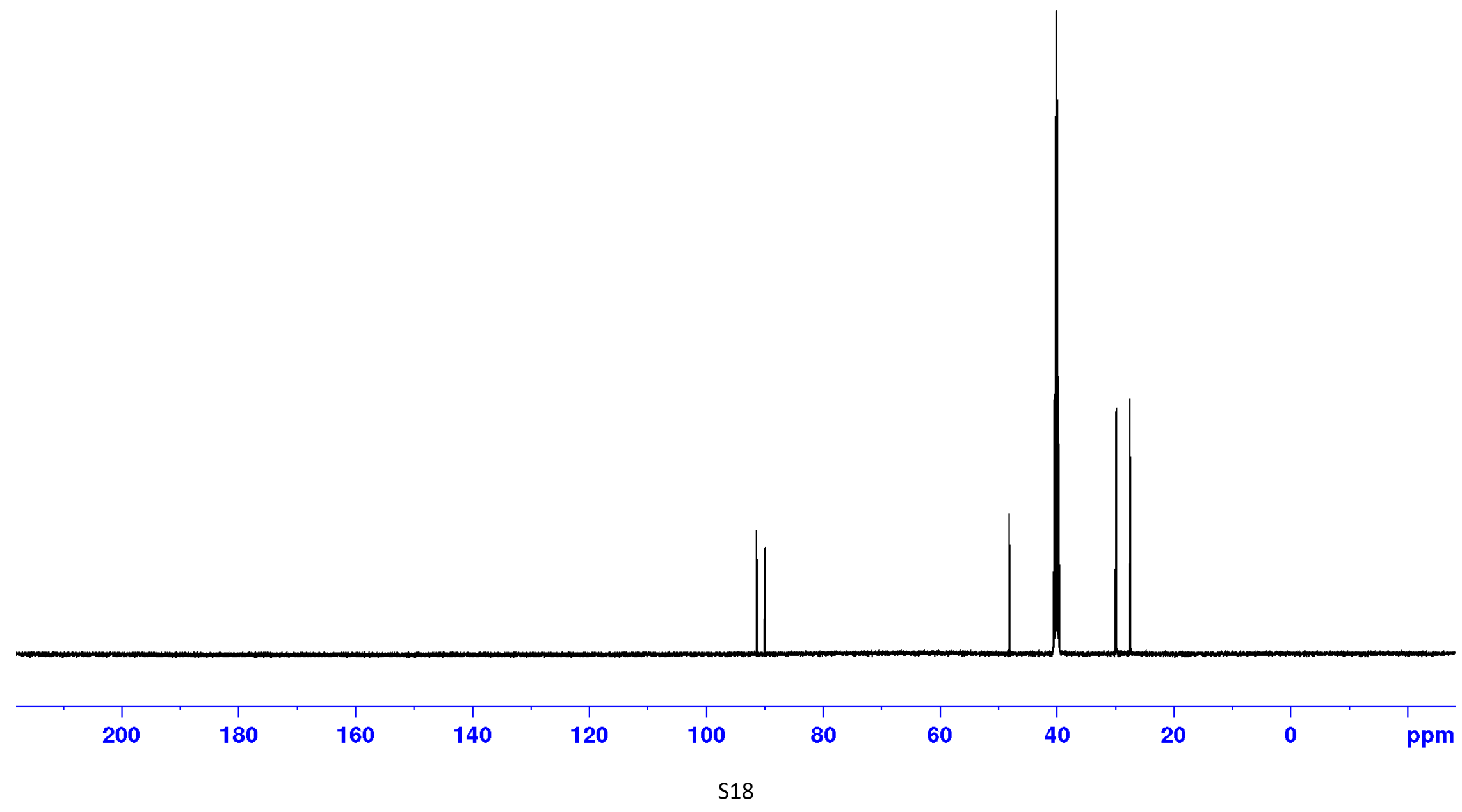


${ }^{19} \mathrm{~F}$ NMR-1a

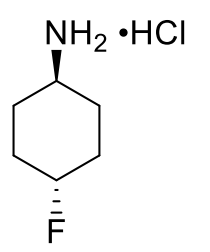

\begin{tabular}{l}
9 \\
0 \\
0 \\
\multirow{2}{*}{+1} \\
1
\end{tabular}

(1a)

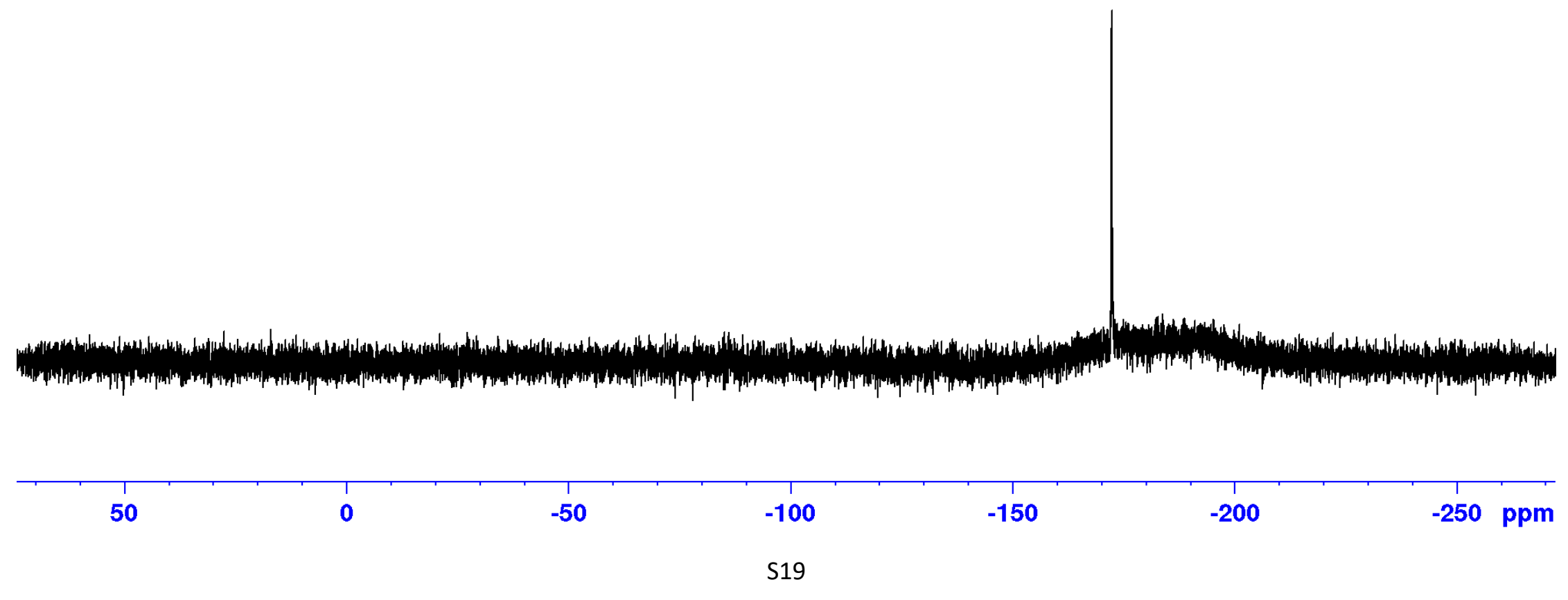

